\title{
Alteration of Hairpin Ribozyme Specificity Utilizing PCR
}

\author{
Paula DeGrandis, Arnold Hampel, ${ }^{1}$ Scott Galasinski, ${ }^{1}$ James Borneman, Andrew Siwkowski, ${ }^{1}$ \\ and Mitchell Altschuler
}

\footnotetext{
${ }^{1}$ Department of Biological Science and Center for Biochemical and Biophysical Studies; Plant Molecular Biology Center and Department of Biological Sciences, Northern Illinois University, DeKalb, Illinois 60115
}

\begin{abstract}
We have developed a method by which a researcher can quickly alter the specificity of a trans hairpin ribozyme. Utilizing this PCR method, two oligonucleotides, and any target vector, new ribozyme template sequences can be generated without the synthesis of longer oligonucleotides. We have produced templates with altered specificity for both standard and modified (larger) ribozymes. After transcription, these ribozymes show specific cleavage activity with the new substrate $\beta$-glucuronidase (GUS), and no activity against the original substrate (HIV-1, $5^{\prime}$ leader sequence). Utilizing this technique, it is also possible to produce an inactive ribozyme that can be used as an antisense control. Applications of this procedure would provide a rapid and economical system for the assessment of trans ribozyme activity.
\end{abstract}

$\mathbf{T}$ he ability of catalytic RNA to specifically cleave and down-regulate viral or endogenous RNA holds great promise with respect to gene therapy. A number of laboratories are adapting and testing such catalytic RNA or ribozymes for use in both in vitro and in vivo systems. ${ }^{(1-4)}$ Of particular interest to our laboratory is the hairpin ribozyme that is active at physiological conditions. ${ }^{(5,6)}$ The only major targeting requirement is the presence of a $B N^{*} G U C$ sequence within the substrate, where $B$ can be any standard nucleotide except an A; in this sequence, cleavage occurs at the asterisk. Hairpin ribozyme design therefore begins by identifying such BNGUC sites within a potential target RNA. Presently, however, there are few empirical rules for targeting domains with respect to increasing the efficiency of catalytic cleavage. Current hairpin design parameters include incorporating a 4-base complementary region 5' to the NGUC and a 6to 10 -base complementary region on the $3^{\prime}$ of the NGUC sequence (Fig. 1). The optimal length of the base pairing on the $3^{\prime}$ end is determined by cleavage rates obtained from in vitro cleavage reactions. Using these rules and testing a number of hairpin ribozymes targeting many sequences, we have occasionally designed hairpin ribozymes that show little if any in vitro cleavage activity. Presently, there is no way to predict which target sites show decreased activity. In such cases, we need to change the ribozyme target site, transcribe new ribozyme, and determine its activity. We have therefore developed a method based on PCR by which one could rapidly alter the targeting domains of a hairpin ribozyme from one sequence to an- other. As a result, researchers can change hairpin ribozyme targets with great efficiency. In addition, we have designed an alternative method by which a mutant ribozyme (noncleaving ribozyme) can be produced to measure antisense inhibition versus cleavage effects of the ribozyme for in vivo applications.

\section{MATERIALS AND METHODS}

\section{Target Plasmids}

The plasmids used in these experiments contained hairpin ribozymes (Fig. 2A-C) that were engineered to target specific domains within the human immunodeficiency virus (HIV) 5 ' leader region (pRTHIV, pRTtHIV, pRTHR). Both pRTtHIV and pRTHIV constructs include a cis-cleaving hairpin cassette, ${ }^{(2)}$ which is located $3^{\prime}$ to the trans ribozyme. To determine whether this PCR method could amplify larger, modified ribozymes, we also used as a PCR template pRTtHIV, which incorporates a 201-nucleotide tRNA-like sequence from brome mosaic virus (BMV) between the trans ribozyme and the cis-cleaving cassette. ${ }^{(8-10)}$

\section{Primer Design}

The primers were synthesized on a $381 \mathrm{~A}$ or 392 Applied Biosystems DNA synthesizer and purified by HPLC. A number of primers included restriction enzyme linkers (XbaI and SstI), which were followed by GC clamps, whereas others included the T7 promoter sequence (see Table 1).

\section{PCR Conditions}

We used the standard PCR reaction con- 


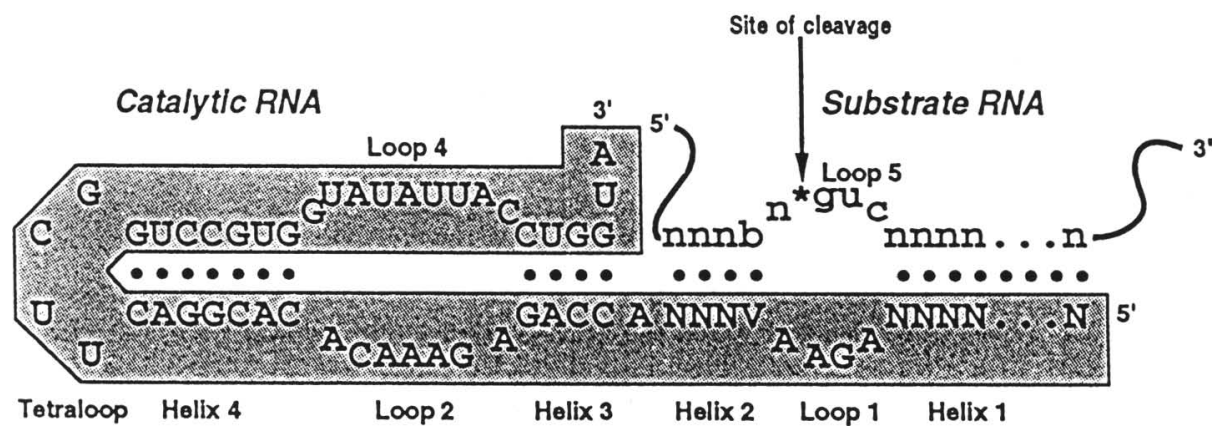

FIGURE 1 Two-dimensional model of the tetraloop hairpin ribozyme. The ribozymes used in these studies differ from the native catalytic domain in helices 1 and 2 (targeting region) and also incorporate the addition of a 12-nucleotide sequence containing a stable tetraloop sequence, ${ }^{(7)}$ which extends helix 4 and replaces loop 3 .

ditions as described by the Taq polymerase manufacturer (Perkin-Elmer). Briefly, a $100-\mu \mathrm{l}$ reaction included $0.1 \mu \mathrm{g}$ of template, $100 \mathrm{~mm}$ each dNTP, $10 \mu \mathrm{l}$ of PCR buffer II, $0.5 \mu \mathrm{M}$ each primer, 2.5 units of AmpliTaq, and $2 \mathrm{~mm} \mathrm{MgCl}_{2}$. All PCR experiments were cycled at $95^{\circ} \mathrm{C}$ for $1 \mathrm{~min}, 53^{\circ} \mathrm{C}$ for $2 \mathrm{~min}$, and $72^{\circ} \mathrm{C}$ for 3 min (with a 5 -sec increase for each extension reaction) for 30 cycles.

\section{DNA Isolation}

PCR products were isolated from a lowmelting-point agarose gel, weighed, and digested with $\beta$-agarase enzyme as described by the manufacturer's instructions (New England Biolabs). The isolated products were digested overnight with $X b a I$ and SstI in a 50- $\mu$ l reaction and cloned into a transcription vector (pTZ19U) cut with the same restriction enzymes using standard cloning techniques. $^{(11)}$

\section{Transcription and Ribozyme Isolation}

Plasmids were prepared for transcription by cutting with EcoRI, phenol extracted, and precipitated. The transcriptions were performed using the Ambion MAXIscript system. The conditions were as follows: In a $10-\mu$ l reaction with $0.5 \mu \mathrm{g}$ of DNA template restricted with EcoRI, 1 $\mu \mathrm{l}$ each of $10 \mathrm{~mm}$ ATP, GTP, and UTP, 5 $\mu \mathrm{l}$ of $0.1 \mathrm{~mm}$ CTP, $0.5 \mu \mathrm{l}$ of RNase inhibitor, $0.5 \mu$ l of T7 RNA polymerase, and 5 $\mu l$ of $\left.{ }^{32} \mathrm{P}\right] \mathrm{CTP}$. The reaction was carried out at $37^{\circ} \mathrm{C}$ for $2 \mathrm{hr}$. Reactions were stopped after $2 \mathrm{hr}$ by the addition of for- mamide-loading dye. Samples were heated at $80^{\circ} \mathrm{C}$ for $2 \mathrm{~min}$ and cooled on ice for $2 \mathrm{~min}$ before loading on the gel. Ribozymes and substrates were isolated from $6.6 \%$ and $15 \%$ denaturing polyacrylamide gels, respectively. To extract the transcribed RNA, gel slices were ground in $300 \mu \mathrm{l}$ of RNA extraction solution $(0.5 \mathrm{M}$ ammonium acetate, 0.5 $\mathrm{mg} / \mathrm{ml}$ of SDS, $2 \mathrm{~mm}$ EDTA). The tubes were then vortexed for $1 \mathrm{hr}$ and spun in a microcentrifuge tube for $20 \mathrm{~min}$, and the supernatant was precipitated with 1 $\mu l$ of glycogen (Boehringer Mannheim, $20 \mathrm{mg} / \mathrm{ml}$ ) and $1 \mathrm{ml}$ of ethanol. After an overnight precipitation at $-20^{\circ} \mathrm{C}$, the RNA was pelleted by centrifugation, and the resulting pellet was subsequently washed with $70 \%$ ethanol and dried. The RNA was then counted in a scintillation counter and quantitated.

\section{Cleavage Conditions}

The ribozyme and substrate concentrations were adjusted to 0.02 and $0.04 \mu \mathrm{M}$, respectively. The cleavage reaction was performed as follows: A 2:1 ratio of substrate to ribozyme was obtained by adding $1 \mu \mathrm{l}$ of ribozyme, $1 \mu \mathrm{l}$ of substrate and $4 \mu \mathrm{l}$ of water. From this solution, 3 $\mu l$ was transferred into two new tubes to be used as 0 - and 30 -min time points. To the 0 -time point tube, $4 \mu$ l of formamide dye was added. This was followed by the addition of $1 \mu \mathrm{l}$ of $4 \times$ cleavage buffer (160 mM Tris at $\mathrm{pH} 7.5,48 \mathrm{mM} \mathrm{MgCl}_{2}, 8$ mM spermidine), to both the 0 - and 30 min reactions. Incubation was then carried out for $30 \mathrm{~min}$ at $37^{\circ} \mathrm{C}$ for both tubes. After incubation, $4 \mu \mathrm{l}$ of formamide dye was added to the 30 -min tube and the products were separated on a $15 \%$ denaturing polyacrylamide gel.

\section{RESULTS}

The hairpin ribozyme structure used in these studies includes four helices and three loops (Fig. 1). In vitro analysis has demonstrated that helices 1 and 2 can be changed such that the targeting of any mRNA is possible as long as it includes the BNGUC sequence. ${ }^{(12)}$

In these studies we have altered three plasmids, each containing a modified ribozyme (pRTHR, pTHIV, and pTtHIV). Contained within all these constructs was an HIV-1, 5' trans ribozyme target $^{(13,14)}$ that we wanted to convert into a $\beta$-glucuronidase (GUS) mRNA targeting ribozyme. The plasmid pRTHIV contains a trans ribozyme sequence followed by a cis hairpin cassette (Fig. 2A), pRTtHIV included an additional 201-nucleotide tRNA-like sequence between a HIV trans ribozyme and the cis cassette (Fig. 2B), and pRTHR had only a trans ribozyme (Fig. 2C).

To design the $5^{\prime}$ PCR oligonucleotides, we needed to convert the information within a chosen mRNA target, in this case, GUS, a marker enzyme from Escherichia coli $^{(15)}$ on a genetic target (Fig. 3A). In this example, $B^{4}$ must be $G$, $C$, or $U$, but not $A$, which is based on previously established rules. ${ }^{(12)}$ The GUS target follows these rules because $B^{4}$ is C. The next nucleotide downstream can be any standard nucleotide. The sequence GUC then follows. $\mathrm{N}^{1}-\mathrm{N}^{4}$ represent helix 2 and must remain 4 nucleotides in length. This is in contrast to helix 1 , which can vary in size. To make the correct oligonucleotide, $\mathrm{N}^{1}$ of the target is converted to the complement nucleotide of the ribozyme and replaces $\mathrm{N}^{1}$ in the 5' PCR oligonucleotide. This step is repeated for the rest of helix $2\left(\mathrm{~N}^{1}-\mathrm{N}^{4}\right)$ and helix $1\left(\mathrm{~N}^{5}-\mathrm{N}^{10}\right)$. The NGUC sequence between helix 1 and helix 2 is replaced by AGAA as needed to maintain the active loop 1 region (see Fig. 1) of the hairpin ribozyme. ${ }^{(12)}$ As shown in Figure $3 A$, the $3^{\prime}$ end of the $5^{\prime}$ oligonucleotide has 17 bases of homology with helix 3 and loop 2 of the hairpin ribozyme.

Of equal interest to this study is the AAA sequence internal to the 17-nucleotide sequence, which was changed in another oligonucleotide ( $5^{\prime}$ mutant PCR oligonucleotide) to CGT (Fig. 3A). This mutation is known to prevent in vitro 


$$
\pi
$$

promoter

1

EcoRI Sacl Kppl Smal Xtor

255 GaATTCGAOCTCGGTACCCGGGGATCCTCGAGACACAACAAGAAGGCAACCAGAGAAACACACGGACTTCGGTCCGTGGTATATTACCTGG

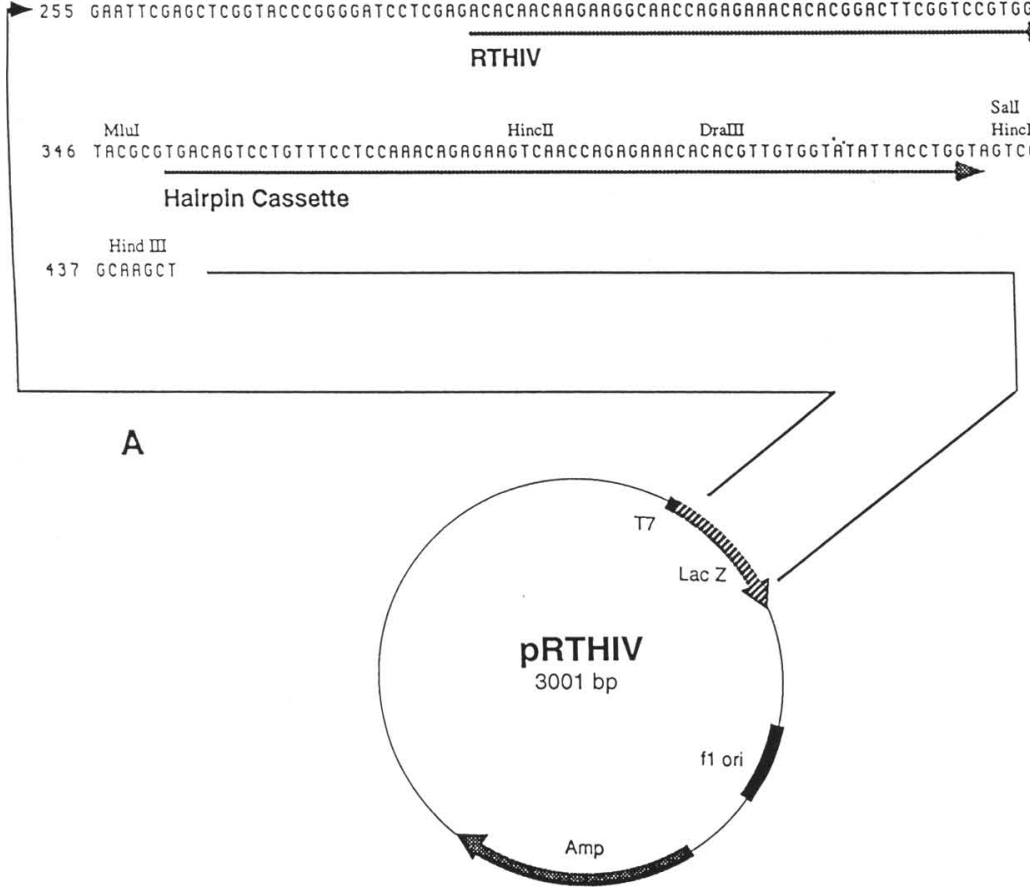

$T 7$

promoter

\rangle$_{\text {ECORI }}$

255 GAATTCACACA

HinCI
350 ATCAGTACARTAACTGATAGTCGTGTIGACAC

tRNA-like Stucture

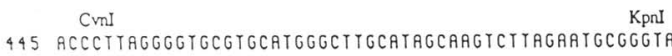

445 ACCCTTAGGGGTGCGTGCATGGGCTIGCATAGCAAGTCTTAGAATGCGGGTACCGTACAGTGTTGAAAAACACTG TAAATCTCTRAAAGAGACCA

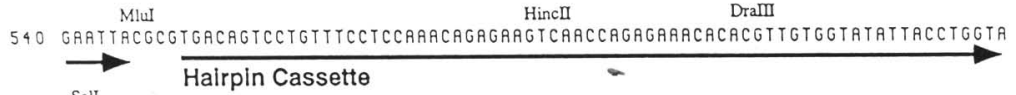

$$
\begin{aligned}
& \text { Sall } \\
& \text { HincI Psu SphI Hindm }
\end{aligned}
$$

618 GTCOACCTTCAGOCATGCAAGCT

\section{B}

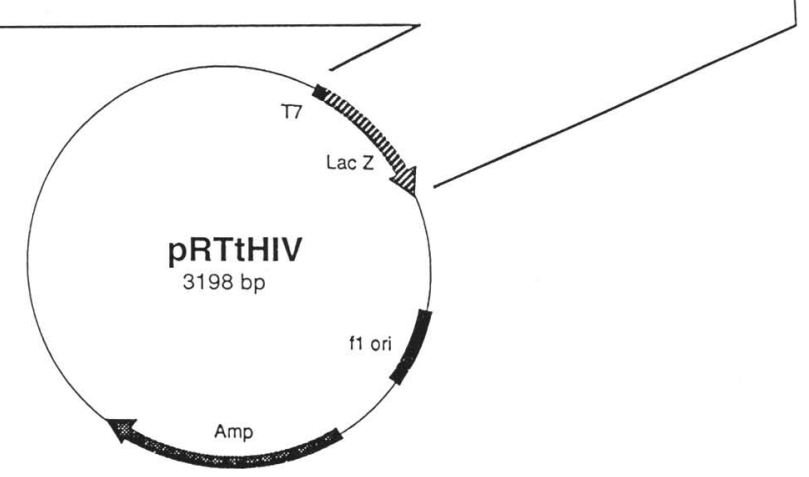

17

promoter

$\downarrow E_{\mathrm{CORI}}$

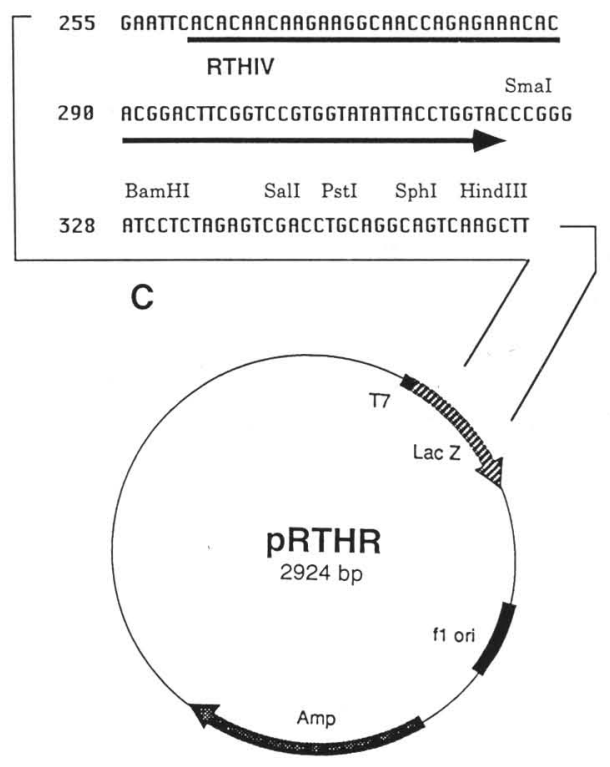

FIGURE 2 Plasmid maps of the HIV ribozyme templates for PCR. $(A)$ Plasmid pRTHIV incorporates a trans HIV ribozyme that targets the $5^{\prime}$ leader and a cis self-cleaving cassette. (B) Plasmid pRTtHIV is very similar to pRTtHIV but contains the tRNA-like sequence from BMV between the trans ribozyme and cis cassette. (C) Plasmid pRTHR contains only a trans HIV 5 ' leader ribozyme.

activity and is, therefore, a good antisense control. ${ }^{(13)}$ To clone any PCR fragments generated we have included a $X b a I$ site on the $5^{\prime}$ end of both the $5^{\prime}$ active and mutant PCR oligonucleotides (Fig. 3B). Because the $3^{\prime}$ end of any cis or trans ribozyme is homologous, we designed the 3 ' oligonucleotide to be com- plementary to the polylinker region just downstream from the cis cassette in pRTHIV and pRTtHIV, and to the trans ribozyme in pRTHR. This oligonucle- 
TABLE 1 Sequences of Oligomers Used for PCR of Ribozymes or Transcription of HIV or GUS Substrates

\begin{tabular}{|c|c|}
\hline Sequence & Oligomer \\
\hline 5'-TAATACGACTCACTATA-3' & T7 primer \\
\hline 5'-GGGAGCTCCATGCCTGCAGGTCG-3' & $3^{\prime}$ PCR \\
\hline 5'-GGGTCTAGATGAGTAGAAGCATACCAGAGAAACACACGG-3' & $5^{\prime}$ active PCR \\
\hline 5'-GGGTCTAGATGAGTAGAAGCATACCAGAGCGTCACACGG-3' & $5^{\prime}$ mutant PCR \\
\hline 5'-ATGAGTGACCGCATCGCTATAGTGAGTCGTATTA-3' & GUS substrate \\
\hline 5'-ACACAAGAGACGGGCACGCTATAGTGAGTCGTATTA-3' & HIV substrate \\
\hline
\end{tabular}

\section{A}

GENERIC TARGET

GUS TARGET 379

\begin{abstract}
GENERIC OLIGO DESIGN
5' ACTIVE PCR GUS OLIGO

5' MUTANT PCR GUS OLIGO
\end{abstract}

B

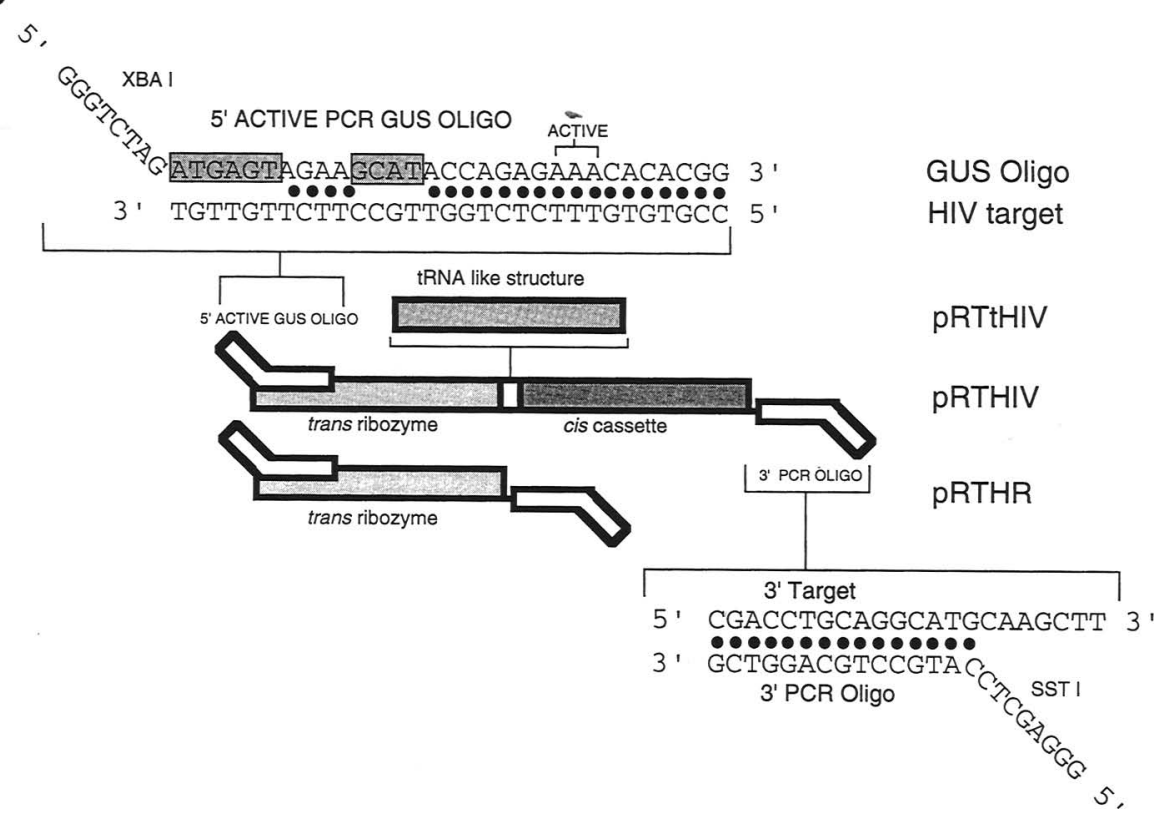

FIGURE $3(A)$ Strategy for determining target domains within a specific mRNA and a method by which both active and mutant $5^{\prime}$ PCR oligonucleotides can be designed. $(B)$ Scheme by which new GUS-specific ribozymes (both modified and un-modified) are generated from a plasmid encoding the HIV 5' leader target. otide also includes a $3^{\prime}$ SstI restriction site for cloning (Fig. 3B). Therefore, as designed, these oligonucleotides should be complementary to all three templates (pRTHIV, pRTtHIV, and pRTHR). Following PCR, cloning, and transcription, three modified ribozyme sequences that target GUS mRNA and not HIV 5' leaders should be generated (Fig. 3B).

PCR amplification from the target plasmids generated bands of the expected sizes (Fig. 4). Plasmid pRTtHIV amplified the largest band of $397 \mathrm{bp}$ (Fig. 4, lane 1), pRTHIV generated a band of 165 bp (Fig. 4, lane 2), and pRTHR a band of $108 \mathrm{bp}$ (Fig. 4, lane 3). Similar patterns were observed when we used a mutant $5^{\prime}$ oligonucleotide that replaced the AAA sequence to CGT (Fig. 4, lanes 4-6). The DNA was isolated and digested with $X b a I$ and SstI and cloned into pTZ19U cut with the same enzymes. Colonies containing inserts were sequenced. All inserts had the selected GUS targeting domains, and no mutations were observed.

We transcribed the active and mutant trans GUS ribozymes that included an active cis cassette. Both PCR-generated sequences (active and mutant) maintained the ability to self-cleave (Fig. 5, lanes $\mathrm{A}, \mathrm{M})$ as expected. To determine the spec-

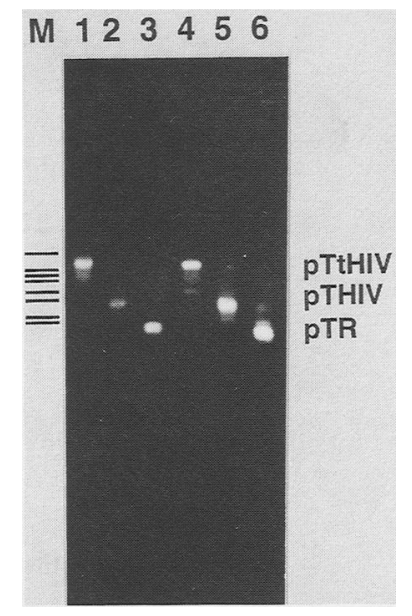

FIGURE 4 Agarose gel analysis (2\%) of PCR reactions on pRTtHIV (lanes 1,4), pRTHIV (lanes 2,5), and pRTHR (lanes 3,6). Primers used were the $5^{\prime}$ PCR active oligonucleotide and $3^{\prime}$ PCR oligonucleotide (lanes 1-3) and the $5^{\prime}$ PCR mutant oligonucleotide and $3^{\prime}$ PCR oligonucleotide (lanes 4-6). The marker lane (M) represents the 516-, 394-, 344-, 298-, 220-, 200-, 154-, 142-, and 75-bp fragments from the 1-kb DNA ladder (GIBCO BRL, Gaithersberg, MD). 


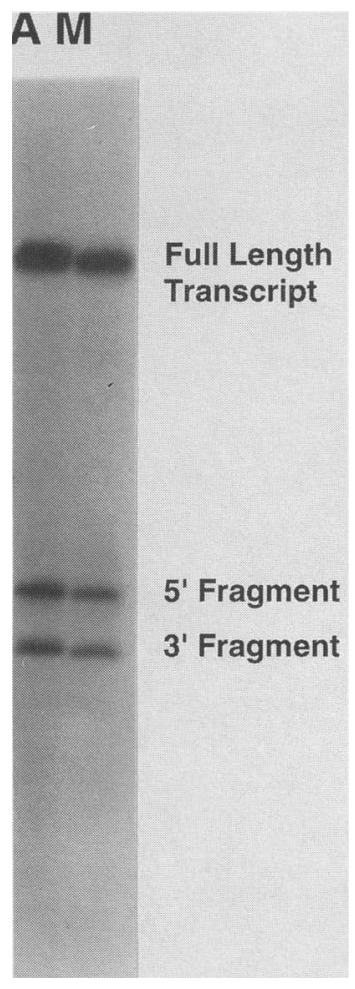

FIGURE 5 In vitro transcription and gel analysis ( $15 \%$ acrylamide) of the active GUS ribozyme (lane $A$ ) and mutant GUS ribozyme (land $M$ ). The full-length transcript (191 nucleotides) should be cleaved into the active or mutant 5' trans ribozyme fragment (102 nucleotides) and the $3^{\prime}$ fragment (89 nucleotides).

ificity of the resulting GUS ribozymes, the active and mutant trans ribozymes were used in cleavage assays against either the GUS or HIV substrate (Fig. 6). The active GUS ribozyme produced cleavage products after $30 \mathrm{~min}$ (Fig. 6 , lane 2), whereas the same ribozyme was inactive against the HIV substrate (Fig. 6 , lane 4). In addition, the replacement of AAA with CGT, which should result in an inactive ribozyme, also inactivated the GUS ribozyme (Fig 6, lane 6). The HIV substrate was shown to be capable of being cleaved when used in a cleavage reaction with an HIV ribozyme, and products were observed (Fig. 6, lane 10).

\section{DISCUSSION}

We were interested in being able to efficiently alter hairpin ribozyme targeting domains to produce varied ribozymes economically. Currently, large numbers of oligonucleotides are used to study their in vitro kinetics. ${ }^{(5,6)}$ It would, therefore, be useful if one could alter ribozyme specificity quickly. In this paper we have described a method by which one could identify potential targets for a hairpin ribozyme within a mRNA. Once identified, the sequence could be converted into small oligonucleotides that could generate a ribozyme with new specificity using PCR.

In these initial studies we were concerned with the balance of mismatching in the target domain (contained mostly in the $5^{\prime}$ end of the oligonucleotide) and the base-pairing that is needed for PCR in the 3 ' end. We chose oligonucleotides that contained $17 \mathrm{bp}$ of complementary sequence to ensure a successful reaction. This number of complementary bases worked with no alterations in our standard PCR reaction. For optimal utilization of this technique, that is, a less costly synthesis, we are currently reducing this 17-bp region. Our results show that by using our oligonucleotide design scheme, one can quickly alter ribozyme specificities. Even with the substitution of CGT for AAA, a substitution that reduced base-pairing by 3 bases, the PCR reaction remains robust (Fig. 4). Not only was a large quantity of DNA synthesized, but after sequencing five clones from each PCR reaction, no changes in the predicted DNA sequence were observed (data not shown). The tolerance of such mismatching in the 17-bp region suggests that the $5^{\prime}$ homology might be reduced as a basis for further optimization of this technique.

Although only the GUS ribozymes generated from pRTHIV were tested for cleavage in this study, we have produced PCR templates that, when transcribed, synthesize other modified trans ribozymes. We are currently testing the activity of GUS ribozymes transcribed from pRTtHIV and pRTHR. Previous results with the ribozyme transcribed from pRTtHIV have shown that this modified structure maintains catalytic activity when exposed to cellular lysates over nonmodified controls. ${ }^{(16)}$ Therefore, the use of this structure in trans ribozymes could have great utility for clinical applications. This PCR method would allow us to change target domains on such modified ribozymes without the need for large oligonucleotides or extensive cloning steps.

From these results many other experiment scenarios can be envisioned. In these experiments a single targeting vector was used in combination with three

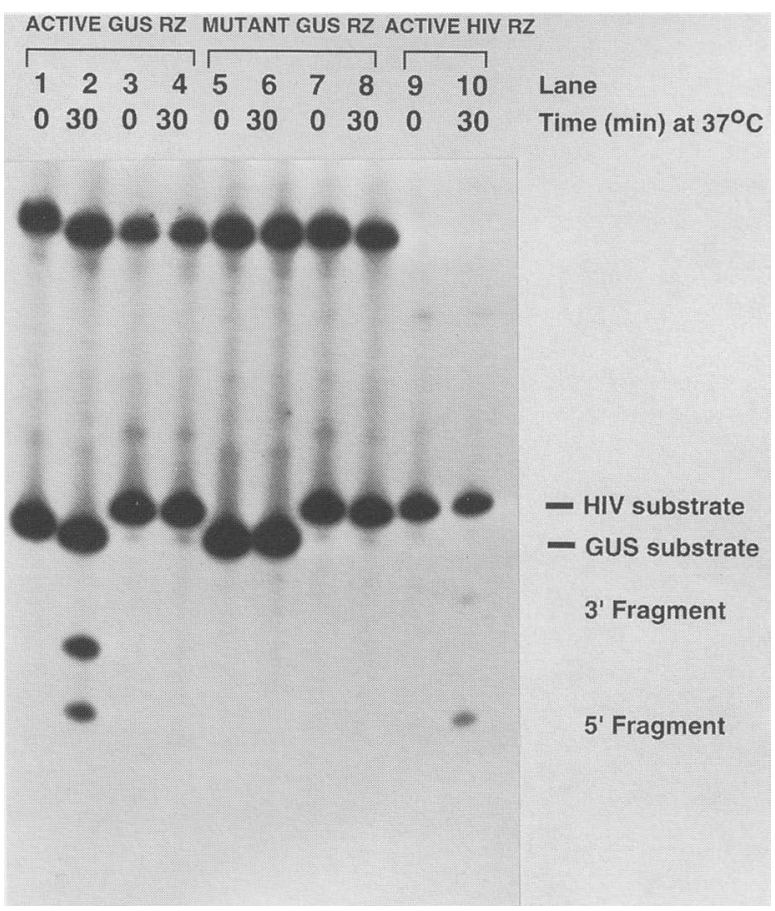

FICURE 6 In vitro cleavage reaction of transcribed GUS ribozymes from PCR derived reactions. (Lanes 1-4) Active GUS ribozyme; (lanes 5-8) the inactive GUS ribozyme; (lanes 9,10) active HIV (cold) ribozyme. (Lanes 1,2,5,6) GUS substrates; (lanes 3,4,7-10) HIV substrates. Incubations were for 0 (lanes $1,3,5,7,9$ ) or 30 min (lanes $2,4,6,8,10$ ) at $37^{\circ} \mathrm{C}$. 
PCR oligonucleotides ( $5^{\prime}$ active, $5^{\prime} \mathrm{mu}$ tant, and 3' PCR oligonucleotide). Alternatively, a dual vector system might be more efficient, in which a truncated $5^{\prime}$ oligonucleotide could amplify from an individual plasmid containing an active or mutant target. This could reduce the size of the $5^{\prime}$ oligonucleotide needed. Other possibilities include engineering a T7 promoter on the $5^{\prime}$ oligonucleotide for transcription without cloning. ${ }^{(17)}$

\section{ACKNOWLEDGMENTS}

We thank the Plant Molecular Biology Center at Northern Illinois University and Biotechnology Research and Development Corporation for funding aspects of this research.

\section{REFERENCES}

1. Cech, T.R., A.J. Zuag, and P.J. Grabowski. 1981. In vitro splicing of the ribosomal RNA precursor of Tetrahymena: Involvement of a guanosine nucleotide in the excision of the intervening sequence. Cell 27: 487-496.

2. Altschuler, M., R. Tritz, and A. Hampel. 1992. A method for generating transcripts with defined $5^{\prime}$ and $3^{\prime}$ termini by autolytic processing. Gene 122: 85-90.

3. Shub, D., C. Peebles, and A. Hampel. Ribozymes. 1994. In RNA processing-A practical approach. Chapter 8, 1-33. Oxford University Press, New York.

4. Sarver, N., A. Hampel, E.M. Cantin, M.I. Johnston, P.S. Chang, and J.J. Rossi. 1990. Exploring catalytic RNAs (ribozymes) as anti-HIV agents. In Gene regulation, oncogenes, and AIDS. 305-325.

5. Hampel, A. and R. Tritz. 1989. RNA catalytic properties of the minimum (-) sTRSV sequence. Biochemistry 28: 49294933.

6. Hampel, A., R. Tritz, M. Hicks, and P. Cruz. 1990. "Hairpin" catalytic RNA model: Evidence for helices and sequence requirement for substrate RNA. Nucleic Acid Res. 18: 299-304.

7. Cheong, C., G. Varani, and J. Tinoco. 1990. Solution structure of a unusually stable RNA hairpin, 5 GGAC(UUUG)GUCC. Nature 346: 680-682.

8. Dzianott, A. and J. Bujarski. 1989. Derivation of an infectious viral RNA by autolytic cleavage of in vitro transcribed viral cDNAs. Proc. Natl. Acad. Sci. 86: 48234827.

9. Gallie, D., J. Feder, R. Schimke, and V. Walbot. 1991. Functional analysis of the tobacco mosaic virus. Nucleic Acids Res. 19: 5031-5036.

10. Lahser, F., L. Marsh, and T. Hall. 1993.
Contributions of the brome mosaic virus RNA-3 3'-nontranslated region to replication and translation. J. Virol. 67: 32953303.

11. Sambrook, J., E.F. Fritsch, and T. Maniatis. 1989. In Molecular cloning: A laboratory manual, 2nd ed. Cold Spring Harbor Laboratory Press, Cold Spring Harbor, New York. .

12. Hampel, A., S. Nesbitt, R. Tritz, and M. Altschuler. 1993. The hairpin ribozyme. Methods 5: 37-42.

13. Ojwang, J.O., A. Hampel, D.J. Looney, F. Wong-Staal, and R. Rappaport. 1992. Inhibition of human immunodeficiency virus type-1 (HIV-1) expression by a hairpin ribozyme. Proc. Natl. Acad. Sci. 89: 1080210806.

14. Yu, M., J. Ojwang, O. Tamada, A. Hampel, J. Rapapport, D. Looney, and F. WongStaal. 1993. A hairpin ribozyme inhibits expression of diverse strains of human immunodeficiency virus type 1. Proc. Natl. Acad. Sci. 90: 6340-6344.

15. Jefferson, R.A. 1987. Assaying chimeric genes in plants: The GUS gene fusion system. Plant Mol. Biol. Rep. 5: 387-405.

16. DeGrandis, P., A. Hampel, C. Lord, and M. Altschuler. (in prep.).

17. Milligan, J., D. Groebe, G. Witherall, and D. Uhlenbeck. 1987. Oligoribonucleotide synthesis using T7 RNA polymerase and synthetic DNA templates. Nucleic Acids Res. 15: 8783-8798.

Received July 5, 1994; accepted in revised form October 14, 1994. 


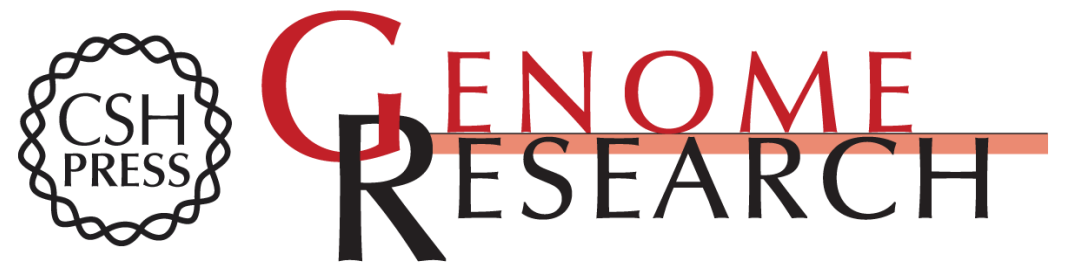

\section{Alteration of hairpin ribozyme specificity utilizing PCR.}

P DeGrandis, A Hampel, S Galasinski, et al.

Genome Res. 1994 4: 139-144

References This article cites 13 articles, 4 of which can be accessed free at:

http://genome.cshlp.org/content/4/3/139.full.html\#ref-list-1

\section{License}

Email Alerting Receive free email alerts when new articles cite this article - sign up in the box at the Service top right corner of the article or click here.

\section{Affordable, Accurate Sequencing.}

To subscribe to Genome Research go to: https://genome.cshlp.org/subscriptions 